\title{
The Out-of-Body Experience: Disturbed Self-Processing at the Temporo-Parietal Junction
}

OLAF BLANKE and SHAHAR ARZY

Folk psychology postulates a spatial unity of self and body, a "real me" that resides in one's body and is the subject of experience. The spatial unity of self and body has been challenged by various philosophical considerations but also by several phenomena, perhaps most notoriously the "out-of-body experience" (OBE) during which one's visuo-spatial perspective and one's self are experienced to have departed from their habitual position within one's body. Here the authors marshal evidence from neurology, cognitive neuroscience, and neuroimaging that suggests that OBEs are related to a failure to integrate multisensory information from one's own body at the temporo-parietal junction (TPJ). It is argued that this multisensory disintegration at the TPJ leads to the disruption of several phenomenological and cognitive aspects of selfprocessing, causing illusory reduplication, illusory self-location, illusory perspective, and illusory agency that are experienced as an OBE. NEUROSCIENTIST 11(1):16-24, 2005. DOI: 10.1177/1073858404270885

KEY WORDS Illusion, Autoscopic phenomena, Temporo-parietal junction, Neurology, Neuroimaging

\section{Self and the Out-of-Body Experience}

In an out-of-body experience (OBE), people seem to be awake and feel that their "self," or center of experience, is located outside of the physical body. It is from an elevated extrapersonal location that the subjects who undergo an OBE (OBErs) experience seeing their body and the world. The following example from Irwin (1985; case 1) may illustrate what subjects experience during an OBE:

I was in bed and about to fall asleep when I had the distinct impression that "I" was at the ceiling level looking down at my body in the bed. I was very startled and frightened; immediately [afterward] I felt that, I was consciously back in the bed again.

An OBE is defined by the presence of three phenomenological characteristics: disembodiment (location of the self outside one's body), the impression of seeing the world from a distant and elevated visuo-spatial perspective (extracorporeal egocentric perspective), and the impression of seeing one's own body (or autoscopy) from this elevated perspective (Green 1968; Blackmore 1982; Blanke and others 2004). This is shown in Figure 1. This threefold deviance from the normal self during

The authors are supported by the Leenaards Foundation.

From the Functional Brain Mapping Laboratory, Department of Neurology, University Hospital, Geneva, Switzerland (O.B., S.A.), and the Laboratory of Cognitive Neuroscience, Brain-Mind Institute, Lausanne, Switzerland (O.B.)

Address correspondence to: Olaf Blanke, MD, PhD, Laboratory of Cognitive Neuroscience, Brain-Mind Institute, 1015 Lausanne, Switzerland (e-mail: olaf.blanke@hcuge.ch).
OBEs has notoriously questioned (and continues to put into question) folk psychological notions of humans about their self and body. OBEs challenge the experienced spatial unity of self and body that has been described as the existence of a "real me" that resides in one's body and is the subject of experience (Neisser 1988). Psychologists (Palmer 1978; Blackmore 1982; Irwin 1985), neurologists (Devinsky and others 1989; Grüsser and Landis 1991; Brugger and others 1997; Blanke and others 2004), and philosophers (Metzinger 2003) suggested that OBEs are culturally invariant neuropsychological phenomena. In addition, some of these authors suggested that OBEs are deviant self models due to abnormal brain activation patterns whose scientific investigation might lead to a better understanding of the processes mediating the self under normal conditions.*

Understanding how the brain generates the abnormal self during OBEs is particularly interesting because OBEs not only are found in clinical populations (Devinsky and others 1989; Grüsser and Landis 1991; Brugger and others 1997; Blanke and others 2004) but also appear in approximately $10 \%$ of the healthy population (Blackmore 1982; Irwin 1985). Moreover, OBEs have been described in the majority of the world's cultures (Sheils 1978). Yet there are to date only a few scientific investigations on OBEs, probably because they generally occur spontaneously, are of short duration, and happen only once or twice in a lifetime (Green 1968;

\footnotetext{
*There have been many other theories of out-of-body experiences (OBEs). For example, some have considered the phenomenological data during OBEs as factual evidence that OBEs reflect the actual projection of a subtle, nonphysical aspect of one's personality in extrapersonal space. These authors suggested that OBEs reflect an actual separation of the self from the body and that OBEs provide evidence for human survival after death. See Irwin (1985, p 219-59), Blackmore (1982, p 200-39), and Alvarado (1992) for a critical discussion of these as well as other accounts.
} 


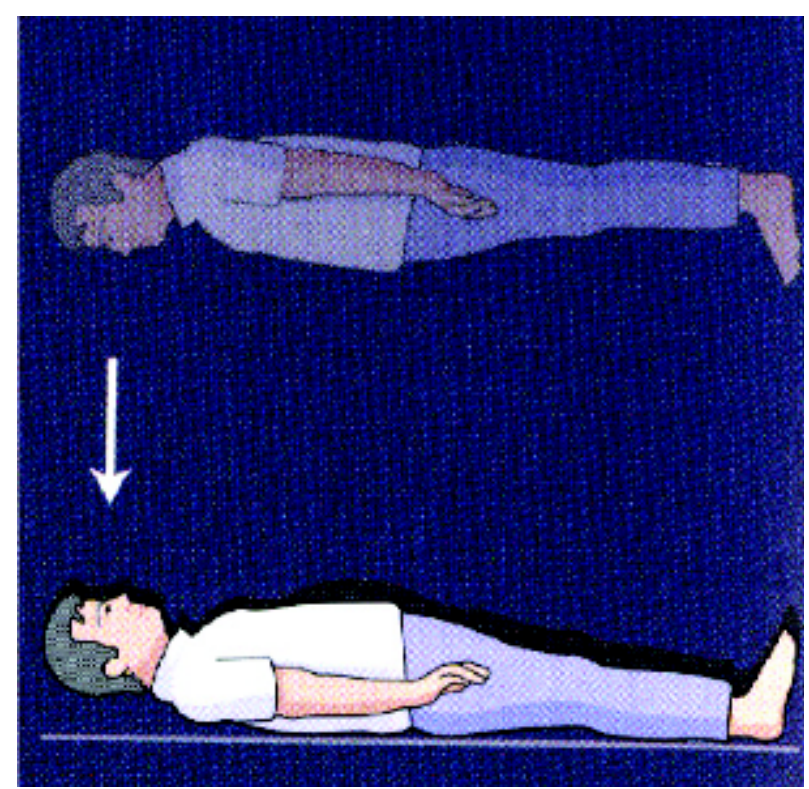

Fig. 1. Phenomenology of out-of-body experience (OBE). During an OBE, the subject appears to "see" himself (bottom) and the world from a location above his physical body (extracorporeal location and visuo-spatial perspective; top). The self is localized outside one's physical body (disembodiment). The direction of the subject's visuo-spatial perspective during an OBE is indicated by an arrow. Modified from Blanke (2004).

Blackmore 1982). This sparseness of scientific investigations is astonishing because other body illusions such as supernumerary phantom limbs or the transformation of an extremity (i.e., visual illusions of body parts) have been systematically investigated by many basic and clinical neuroscientists (for review, see Ramachandran and Hirstein 1998; Halligan 2002). Importantly, these latter studies have led to the description of neurophysiological and neuroanatomical mechanisms of visual illusions of body parts and to the development of more efficient treatments for neurological patients. This is not the case for visual illusions of the entire body such as OBEs, which continue to occupy a neglected position between neuroscience and mysticism. Although several authors in the field of psychology have experimentally investigated OBEs (for review, see Alvarado 2000), the present review will focus on recent neurological and neuroimaging findings with respect to OBEs.

\section{OBEs of Neurological Origin}

Authors in the field of neurology have described several patients with OBEs due to brain damage. This has resulted in descriptions of the etiology, associated phenomenology (such as autoscopic phenomena, vestibular disturbances, and visual body part illusions), and anatomy of OBEs. This is described in detail below.

Early reports were by Lippman (1953, case 1 and 2), Hécaen and Green (1957, case 3), Daly (1958, case 5), and Lunn (1970, case 1). More recently, Devinsky and others (1989, case 1, 2, 3, 6, and 10) and Blanke and others (2004, case 1, 2a, and 3 ) reported further cases show- ing that the phenomenology of OBEs in neurological and healthy subjects is very similar:

Suddenly it was as if he saw himself in the bed in front of him. He felt as if he were at the other end of the room, as if he were floating in space below the ceiling in the corner facing the bed from where he could observe his own body in the bed. . . he saw his own completely immobile body in the bed; the eyes were closed. (Lunn 1970 , case 1)

Etiology. OBEs have been observed predominantly in patients with epilepsy and migraine. Thus, Lippman (1953) reported two migraine patients with OBEs, and Green (1968) reported that $11 \%$ of the OBE subjects that participated in her survey suffered from migraine headaches. Devinsky and others (1989) described the largest study of neurological OBE patients and described patients whose OBE was associated with nonlesional epilepsy (cases 6 and 10), with epilepsy due to an arteriovenous malformation (cases 2 and 3 ) or to posttraumatic brain damage (case 1). In Blanke and others' study (2004), OBEs were due to a dysembryoplastic tumor (cases 1 and 2a) and in one patient induced by focal electrical stimulation (case 3 ).

Autoscopic Phenomena. Authors in the field of neurology have classified OBEs among autoscopic phenomena, which are defined as a group of illusory visual experiences during which the subject has the impression of seeing a second own body in extrapersonal space (Devinsky and others 1989; Brugger and others 1997). Next to OBEs, two other forms of autoscopic phenomena have been described. Devinsky and others (1989) explicitly compared OBEs to phenomenon of autoscopic hallucination, which is defined as the experience of seeing a double of oneself in extrapersonal space without leaving one's body. Autoscopic hallucination is illustrated in the following example:

The patient suddenly noticed a seated figure on the left.

"It wasn't hard to realize that it was I myself who was sitting there. I looked younger and fresher than I do now. My double smiled at me in a friendly way." (Kölmel 1985, case 6)

The third autoscopic phenomenon is heautoscopy, which is an intermediate form between autoscopic hallucination and OBE. During heautoscopy, the subject also sees his double in extrapersonal space, but it may be difficult for the subject to decide whether he is disembodied or not. In fact, subjects may state that they experience seeing the world from two simultaneous or alternating visuo-spatial perspectives (Brugger and others 1994; Blanke and others 2004):

[The patient] awakens from sleep and has the immediate impression as if she were seeing herself from behind herself. She felt as if she were "standing at the foot of my bed and looking down at myself." Yet ... the patient 
also has the impression to "see" from her physical [or bodily] visuo-spatial perspective, which looked at the wall immediately in front of her. Asked at which of these two positions she thinks herself to be, she answered that "I am at both positions at the same time." She did not have the feeling of being out of her body (Blanke and others 2004, case 2b)

To summarize, the three forms of autoscopic phenomena differ with respect to the three phenomenological characteristics of OBEs as defined above (disembodiment, visuo-spatial perspective, autoscopic hallucination). Whereas there is no disembodiment in autoscopy and always disembodiment in OBEs, subjects with heautoscopy generally do not report clear disembodiment but are not able to localize their self easily. Thus, in some cases, the self is localized at multiple positions, including extracorporeal positions. Accordingly, the visuospatial perspective is body centered in autoscopic hallucination, extracorporeal in $\mathrm{OBE}$, and at different extracorporeal positions and the body-centered position in heautoscopy. The impression of seeing one's own body (autoscopy) is present in all autoscopic phenomena (for further details, see Brugger and others 1997; Blanke and others 2004).

Disturbed Own-Body Processing. Whereas Devinsky and others (1989) observed the frequent association of vestibular sensations and OBE, Grüsser and Landis (1991) proposed that a paroxysmal vestibular dysfunction might be an important mechanism for the generation of OBEs. In Blanke and others' (2004) study, the importance of vestibular mechanisms in OBEs is underlined by their presence in all patients with OBEs and by the fact that vestibular sensations were evoked in a patient at the same site where higher currents induced an OBE (Blanke and others 2002). In more detail, it has been suggested that OBEs are associated with specific vestibular sensations, namely, graviceptive (or otholithic), and vestibular sensations (Blanke and others 2004). Otholithic sensations are characterized by a variety of sensations including feelings of elevation and floating, as well as 180-degree inversions of one's body and visuo-spatial perspective in extrapersonal space. They may be associated with brain damage (Smith 1960; Brandt 2000) but also occur in healthy subjects during space missions or the microgravity phase of parabolic flights (Lackner 1992; Mittelstaedt and Glasauer 1993). Interestingly, responses to microgravity may be experienced either as an inversion of the subject's body and visuo-spatial perspective in extrapersonal space (inversion illusion) or as an inversion of the entire extrapersonal visual space, which appears inverted by 180 degrees to the stable observer (room tilt illusion; Lackner 1992; Mittelstaedt and Glasauer 1993). Based on these functional similarities, Blanke and others (2004) suggested that an otholithic dysfunction might be an important causal factor not only for room tilt illusion and inversion illusion but also for OBE.
In addition to vestibular disturbances, it has been reported that OBE patients may also experience paroxysmal visual body-part illusions such as supernumerary phantom limbs, and illusory limb transformations either during the OBE or during other periods related to epilepsy or migraine (Hécaen and Ajuriaguerra 1952; Lunn 1970; Devinsky and others 1989; Blanke and others 2002, 2004). Blanke and others (2002) reported a patient in whom OBEs and visual body-part illusions were induced by electrical stimulation at the right temporoparietal junction (TPJ). In this patient, an OBE was induced repetitively by electrical stimulation whenever the patient looked straight ahead (without fixation of any specific object; Fig. 2A). If she looked at her arms or legs that were stretched out, she had the impression that the inspected body part was transformed, leading to the illusory, but very realistic, visual perception of limb shortening (Fig. 2B,C) and illusory limb movement if the limbs were bent at the elbow or knee (Fig. 2D, 2E). Finally, with closed eyes, the patient did not have either an OBE or a visual body-part illusion but perceived her upper body as moving toward her legs (Blanke and others 2002). These data suggest that visual illusions of body parts and visual illusions of the entire body such as autoscopic phenomena might depend on similar neural structures, as argued by previous authors (Hécaen and Ajuriaguerra 1952; Brugger and others 1997). Blanke and others' (2002) data also show that visual body-part illusions and OBEs are influenced differently by the behavioral state of the subject.

Another phenomenological link between OBE and disturbed own-body perception is suggested by the fact that OBE and autoscopic hallucination depend differently on the patient's position prior to the experience, suggesting that proprioceptive and tactile mechanisms influence both phenomena. Thus, during an OBE, the patients of Blanke and others (2004) were in a supine position, as was found by Green (1968) in 75\% of OBE subjects. Interestingly, most techniques that are used to voluntarily induce OBEs propose that the subjects use a supine and relaxed position (Blackmore 1982; Irwin 1985). On the contrary, patients with autoscopic hallucination or heautoscopy were either sitting or standing. This confirms results by Denning and Berrios (1994), who reviewed a large number of patients with autoscopic hallucination and heautoscopy, suggesting that a closely related cerebral dysfunction might lead to either autoscopy or OBE depending on the patient's body position prior to or during the experience.

Anatomy. Only a few neurological OBE patients with circumscribed brain damage have been described. In some of Devinsky and others' (1989) OBE patients, the seizure focus was estimated only by electroencephalogram recordings and localized to the temporal lobe or posterior temporal region (MRI or computer tomography was normal in most patients; Table 1). Yet, in one patient, the lesion was found in the temporal lobe and in another patient in the frontal and temporal lobe 


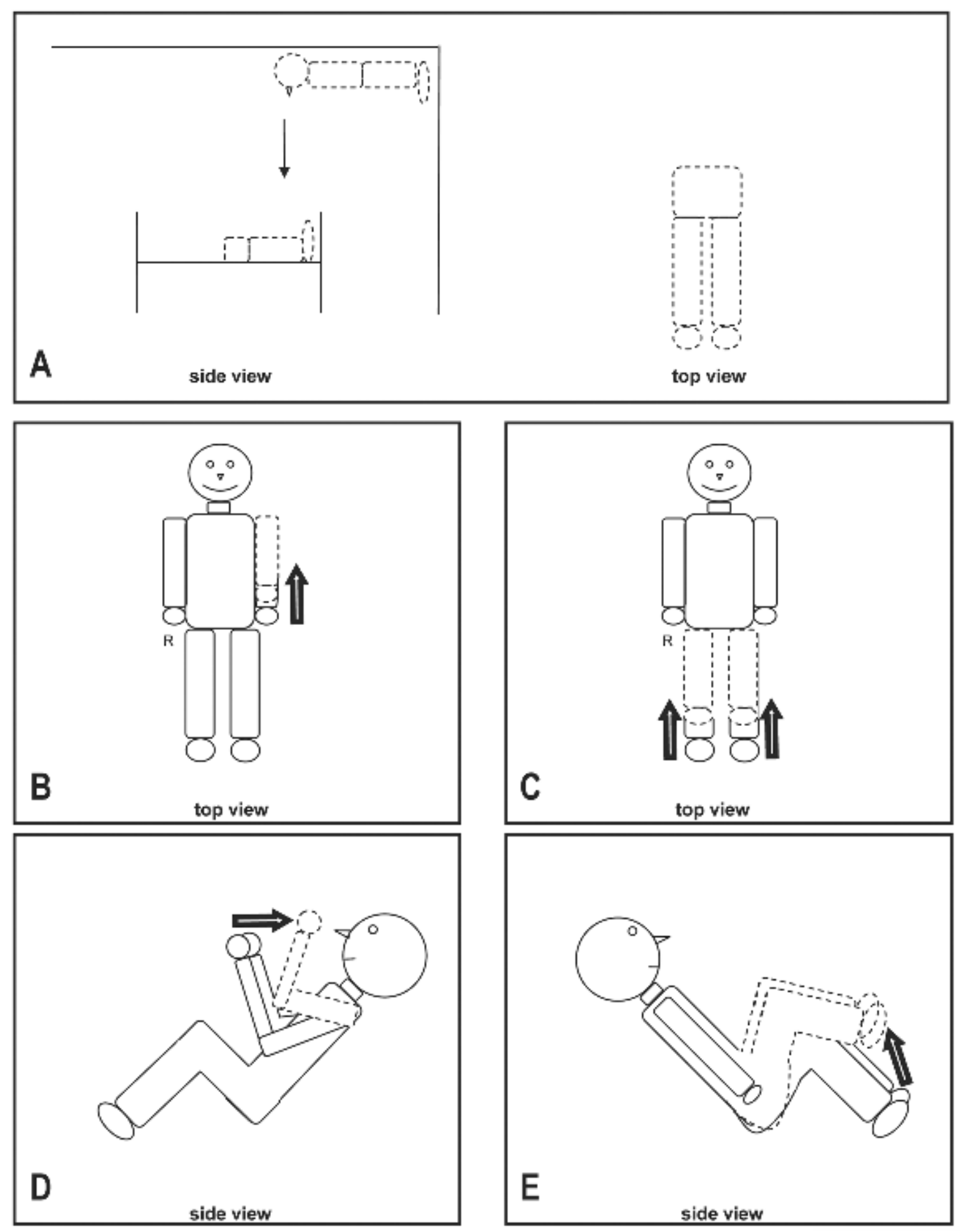

Fig. 2. Out-of-body experience (OBE) and visual body-part illusions as induced by electrical stimulation of the right temporo-parietal junction. $A$, OBE: The patient felt as if "floating" approximately $2 \mathrm{~m}$ above the bed, close to the ceiling and to the right corner of the room (left). She experienced seeing her body as lying in the bed but stated that she saw only the lower trunk of her body (right). $B$, Illusory arm shortening: When asked to look at her outstretched arms during electrical stimulation, the patient felt as though her left arm was shortened; the right arm was unaffected. $C$, Illusory leg shortening: While asked to watch her outstretched legs during electrical stimulation, she reported seeing both legs "becoming shorter." $D$, Illusory arm movement: If both arms of the patient were outstretched but bent by 90 degrees at the elbow during electrical stimulation, she felt that her left lower arm and hand were moving toward her face. $E$, Illusory leg movement: If the patient's legs were bent during electrical stimulation, she reported that both legs appeared to be moving toward her face. The physical body appearance during electrical stimulation is shown in black lines outlining the body. Dashed lines indicate the illusory visual perceptions of the patient with respect to her own body. There were no visual illusions with respect to extrapersonal space (Blanke and others 2002). 
Table 1. Clinical Findings in Previous Neurological Out-of-Body Experience (OBE) Patients with Focal Brain Damage

\begin{tabular}{|c|c|c|c|}
\hline Patient & Hemisphere & Lobe & Etiology \\
\hline Daly (1958), case 5 & Right & Temporal & Seizure (astrocytoma, grade III) \\
\hline Lunn (1970), case 1 & Right & Parietal & $\begin{array}{l}\text { Not known (posttraumatic } \\
\text { shell splinter) }\end{array}$ \\
\hline Devinsky and others (1989), case 1 & Right & Temporo-occipital & Seizure (no lesion reported) \\
\hline Devinsky and others (1989), case 2 & Left & Frontal-temporal & Seizure (no lesion reported) \\
\hline Devinsky and others (1989), case 3 & Right & Temporal & $\begin{array}{l}\text { Seizure (arteriovenous } \\
\text { malformation) }\end{array}$ \\
\hline Devinsky and others (1989), case 6 & Bilateral & Temporal & Seizure (no lesion reported) \\
\hline Devinsky and others (1989), case 10 & Bilateral & Frontal-temporal & Seizure (no lesion reported) \\
\hline Blanke and others (2003), case 1 & Right & Parietal-occipital-temporal & Seizure (DNET) \\
\hline Blanke and others (2003), case $2 a$ & Left & Temporo-parietal & Seizure (DNET) \\
\hline Blanke and others (2003), case 3 & Right & Temporo-parietal & $\begin{array}{l}\text { Electrical stimulation } \\
\text { (normal tissue) }\end{array}$ \\
\hline
\end{tabular}

DNET, dysembryoplastic neuroepithelial tumor. The table summarizes etiology (right column) as well as gyral (middle column) and hemispheric (left column) lesion location in previously reported patients with OBE of neurological origin. These studies reveal that most OBEs are related to focal epilepsy in the right temporal and/or parietal lobe.

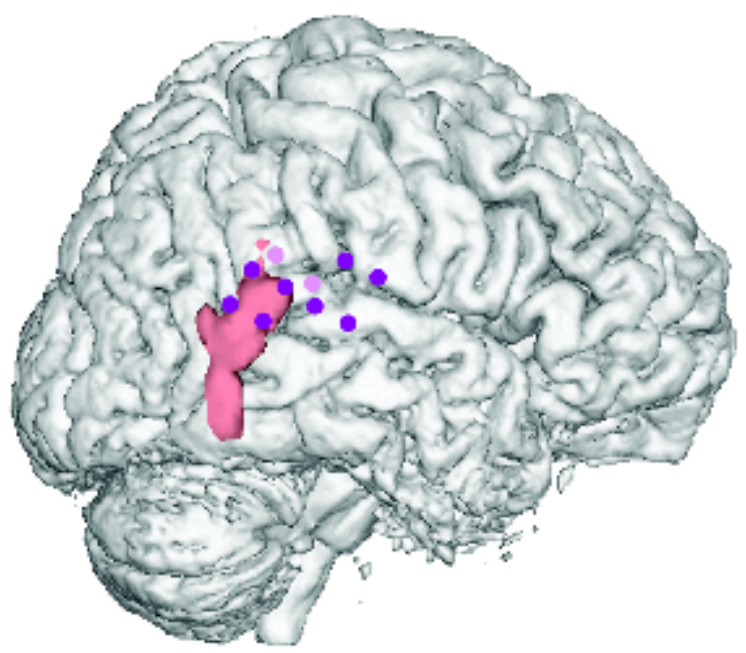

Fig. 3. Lesion location in out-of-body experience (OBE) patients. The MRI-based lesion overlap analysis of the three OBE patients from the study of Blanke and others (2004) is shown. The MRI of all patients was transformed into Talairach space and projected on the MRI of one patient. Each color represents a different OBE patient. In two patients, the OBE site was located by intracranial electrodes during invasive presurgical epilepsy evaluation and in one patient by noninvasive methods for localizing the seizure-onset zone. Note the implication in all patients of the temporo-parietal junction. See Blanke and others (2004) for further details.

(Devinsky and others 1989). Lunn (1970) described an OBE patient with posttraumatic brain damage in the parietal lobe, and Daly (1958) described an OBE patient with damage to the temporal lobe. More recently, Blanke and others (2004) performed lesion analysis based on MRI and showed involvement of the TPJ in all three OBE patients. Moreover, Blanke and others (2002) have shown that OBEs can be induced by electrical stimulation of the TPJ, pointing to the importance of this region in the generation of OBEs. Figure 3 summarizes the lesion results of the OBE patients of Blanke and others (2004). Previous studies found that OBEs related in $75 \%$ of the patients to right hemispheric brain damage. The localization and hemispheric lateralization of brain damage in all previously reported OBE patients due to circumscribed brain damage is summarized in Table 1 .

\section{Multisensory Disintegration at the TPJ Leads to OBEs}

To create a central representation of one's own body (Melzack 1990), the brain must integrate and weigh the evidence from different sensory sources (such as visual, tactile, proprioceptive, and vestibular information) and quickly arrive at a decision. This involves mechanisms for imposing coherence on information from different sensory sources and mechanisms for diminishing incoherences to avoid uncertainty. Thus, the brain must create sensory-central representations of the movement and position of the body and its position in extrapersonal space even if this requires the temporary inhibition of discrepant inputs. For example, discrepant proprioceptive input might be discarded (and regarded as noise) if visual, tactile, and vestibular input about the position and movement of one's own body concur. Yet, in some cases, discrepant input can be very strong and persistent and come from more than one sensory channel, leading to two discrepant central representations of one's own body or body parts, as can also be induced experimentally (Goodwin and others 1972; Lackner 1988). We speculate that during an OBE, the integration of proprioceptive, tactile, and visual information of one's body fails due to discrepant central representations by the different sensory systems. This may lead to the experience of seeing one's body (autoscopy) in a position that does not coincide with the felt position of one's body, as proposed for the affected body part in supernumerary phantom limbs (Ramachandran and Hirstein 1998). As OBEs 
are also characterized by disembodiment and elevated visuo-spatial perspective, we speculate that an additional otholithic vestibular dysfunction is present in OBEs. Thus, as in the inversion illusion (Lackner 1992; Mittelstaedt and Glasauer 1993), the visuo-spatial perspective and body of the OBE subject are experienced at an extracorporeal location that is elevated and inverted by 180 degrees with respect to extrapersonal space due to disintegration between vestibular and extrapersonal sensory information. To summarize, we suggest that OBEs are related to an integration failure of proprioceptive, tactile, and visual information with respect to one's own body (disintegration in personal space) and by a vestibular dysfunction leading to an additional disintegration between personal (vestibular) space and extrapersonal (visual) space. We argue that both disintegrations are necessary for the occurrence of $\mathrm{OBE}$ and that they are due to a paroxysmal cerebral dysfunction of the TPJ.

\section{The TPJ Is a Crucial Structure for Different Aspects of Body and Self-Processing}

The above model of OBEs has been based on phenomenological and anatomical findings in neurological patients with OBEs. This creates a link between the complex phenomenon of the OBE with multisensory disintegration and deficient vestibular information processing at the TPJ. This is not trivial, as these clinical findings may help to demystify OBEs and facilitate a formulation of precise research hypotheses about the sensory and cognitive underpinnings of OBEs (as previous research into the neural bases of complex body-part illusions has done for phantom limbs; Ramachandran and Hirstein 1998; Halligan 2002). The neuroscientific investigation of OBEs may also turn out to be very useful in defining the functions and brain structures mediating such aspects of the normal self such as bodily awareness, embodiment, egocentric visuo-spatial perspective, and self-consciousness.

Neuroimaging studies already support the role of the TPJ in vestibular processing, multisensory integration, and the perception of human bodies or body parts. First, the core region of the human vestibular cortex (Lobel and others 1999; Fasold and others 2002) is situated at the TPJ including the posterior insula. Brain damage in this area has been associated with graviceptive vestibular sensations and dysfunctions (Smith 1960; Brandt 2000). Second, several neuropsychological and neuroimaging studies suggest the implication of the TPJ and cortical areas along the intraparietal sulcus in combining tactile, proprioceptive, and visual information in a coordinated reference frame (Calvert and others 2000). Interestingly, Leube and others (2003) have shown that the TPJ codes multisensory conflict between visual and proprioceptive information about one's arm position, as proposed in the above OBE model for the entire body. Third, the TPJ is also involved in the perception of many different aspects of the human body, including the perception of body parts (Bonda and others 1995) and the entire body (Downing and others 2001; Astafiev and others 2004), as well as biological motion (Grossman and others 2000; Beauchamp and others 2002) and mental imagery with respect to one's own body (Zacks and others 2002; Blanke and others 2003). Importantly, Astafiev and others (2004) have shown that some of these visual areas are modulated not only by visually presented human bodies or body parts but also by limb movements (without visual feedback), suggesting their role in multisensory own-body perception.

The TPJ has also been involved in cognitive functions that are closely linked to self-processing and OBEs: egocentric visuo-spatial perspective taking, agency (the feeling of being the agent of one's actions and thoughts), and self-other distinction (the capacity by which one distinguishes between oneself and other conspecifics). Thus, during OBEs, one's visuo-spatial perspective and one's sense of agency are localized at the position of the disembodied self that is hovering above the physical body. In other words, the self is experienced to look at its body from a third (or other) person's visuo-spatial perspective and position. Furthermore, the TPJ is the classical lesion site in patients with visuo-spatial neglect (Halligan and others 2003), a clinical condition that has been shown to disturb the patient's egocentric spatial relationship with extrapersonal space and visuo-spatial perspective taking (e.g., Farrell and Robertson 2000). Neuroimaging studies in healthy observers have also revealed activation of the TPJ during egocentric visuospatial perspective changes in healthy subjects (Maguire and others 1998; Ruby and Decety 2001). Moreover, neuroimaging studies have also shown that mental activities such as agency and self-other distinction activates the TPJ (Decety and Sommerville 2003). Although many other cortical areas such as the prefrontal cortex, anterior cingulate, postcentral gyrus, precuneus, occipitotemporal junction, insula, and superior parietal lobule (Grossman and others 2000; Ruby and Decety 2001; Beauchamp and others 2002; Zacks and others 2002; Decety and Sommerville 2003; Leube and others 2003) have been shown to play a role in self-processing, the reviewed neuroimaging data on body and selfprocessing as well as the clinical data on OBEs suggest that the TPJ is a key neural locus for self-processing that is involved in multisensory body-related information processing as well as in processing of phenomenological and cognitive aspects of the self (Fig. 4).

\section{Conclusion}

OBEs have fascinated mankind from time immemorial and are abundant in folklore, mythology, and spiritual experiences of most ancient and modern societies. We have reviewed clinical and neuroimaging evidence suggesting that OBEs are culturally invariant brain phenomena that can be investigated using neuroscience. These data suggest an interaction between lower-level vestibular and multisensory processing and higher-level selfprocessing such as egocentric visuo-spatial perspective taking, agency, and self-location. It is hoped that the 


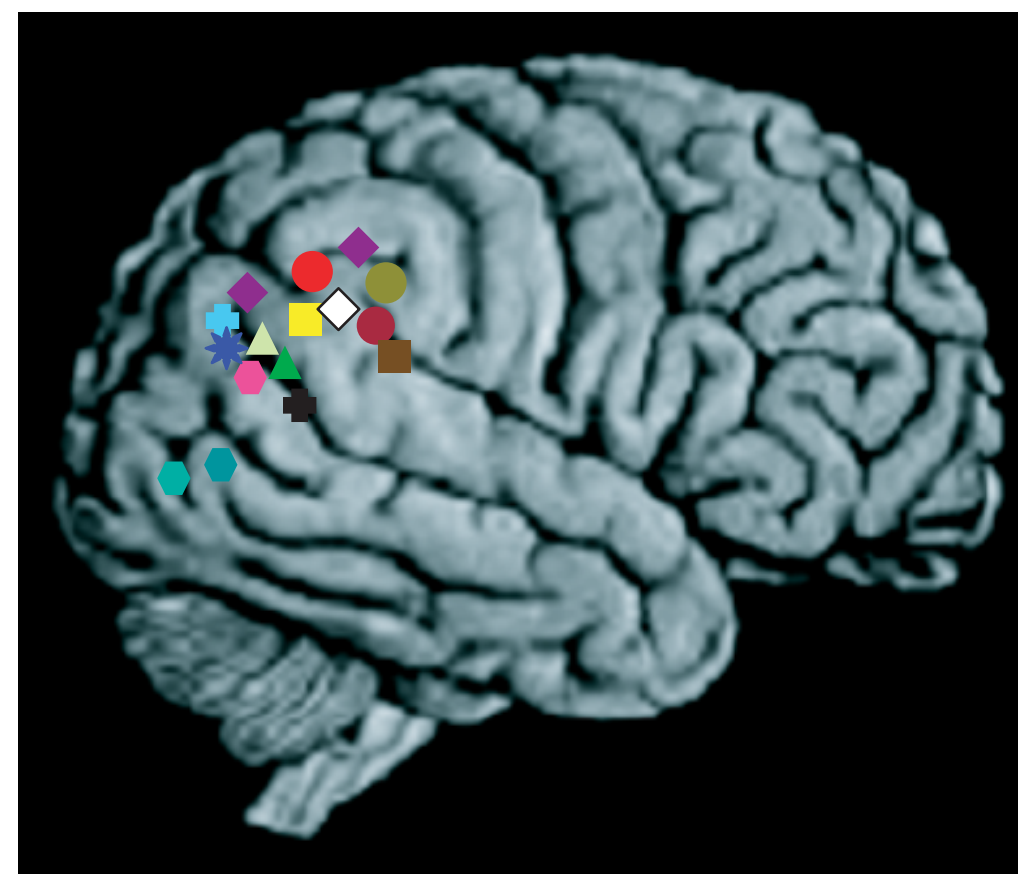

\section{Self-processing:}

$\triangle$ multisensory integration

$\bigcirc$ visuo-spatial perspective

$\square \quad$ vestibular perception

$\diamond$ mental own body imagery

ط biological motion

$\square$ body perception

agency

Halligan and others 2003

Ruby and Decety 2001

Maguire and others 1998

Bonda and others 1995

Downing and others 2001

Astafiev and others 2004

Zacks and others 2002

Blanke and others 2004
Grossman and others 2000

Beauchamp and others 2002

Decety and Sommerville 2003

Calvert and others 2000

Leube and others 2003

Fasold and others 2002

Lobel and others 1998

Fig. 4. Self-processing at the temporo-parietal junction (TPJ). The figure summarizes data from several neuroimaging studies that revealed an activation of the TPJ during different aspects of self-processing such as visuo-spatial perspective taking, agency, selfother distinction, mental own-body imagery, biological motion perception, and vestibular and multisensory perception. Activations during these paradigms that were found in other areas are not shown. An approximate location with respect to the gyral and sulcal surface is given for each study. Most of the results were found in the right TPJ only or showed a right hemisphere dominance.

experimental investigations of the interactions between these sensory and cognitive systems in OBEs and related illusions in combination with neuroimaging and behavioral techniques will further our understanding of the central mechanisms of corporal awareness and selfconsciousness that have long eluded scientific scrutiny.

\section{References}

Alvarado CS. 1992. The psychological approach to out-of-body experiences: a review of early and modern developments. J Psychol $126: 237-50$

Alvarado CS. 2000. Out-of-body experiences. In: Cardena E, Lynn SJ, Krippner S, editors. Varieties of anomalous experiences.
Washington (DC): American Psychological Association. p 183-218.

Astafiev SV, Stanley CM, Shulman GL, Corbetta M. 2004. Extrastriate body area in human occipital cortex responds to the performance of motor actions. Nat Neurosci 7:542-8

Beauchamp MS, Lee KE, Haxby JV, Martin A. 2002. Parallel visual motion processing streams for manipulable objects and human movements. Neuron 34:149-59.

Blackmore SJ. 1982. Beyond the body: an investigation of out-of-body experiences. London: Heinemann.

Blanke O, Safran AB, Landis T, Vishenko S, editors. 2004. Illusions visuelles. In: Neurophtalmologie. Paris: Masson. p 147-50.

Blanke O, Landis T, Spinelli L, Seeck M. 2004. Out-of-body experience and autoscopy of neurological origin. Brain 127:243-58.

Blanke O, Mohr C, Seeck M, Michel CM. 2003. Out-of-body experience and the mental transformation of one's own body. Presented at the 9th International Conference on Functional Mapping of the 
Autoscopic hallucination

Disembodiment

Heautoscopy

Inversion illusion

Out-of-body experience (OBE)

Room-tilt illusion

Sense of agency

Visual body-part illusions

Visuo-spatial perspective
Experience of seeing one's body in extracorporeal space (as a double) without disembodiment. The double is seen from the habitual egocentric visuo-spatial perspective.

Experience that the self is localized outside one's physical body boundaries. Intermediate form between autoscopic hallucination and OBE; the subject experiences seeing his or her body and the world in an alternating (or simultaneous) fashion from an extracorporeal and his bodily visuo-spatial perspective; often, it is difficult for the subject to decide whether the self is localized in the double or in one's own body.

The experience of seeing the world from a location and visuo-spatial perspective that is inverted by 180 degrees with respect to the subject's actual position and perspective. There is neither disembodiment nor autoscopy.

Experience of seeing one's own body and the world from a location that is outside one's physical body (disembodiment). This extracorporeal location and visuo-spatial perspective is generally experienced as inverted by 180 degrees with respect to the subject's actual position.

The experience that the world is inverted by 180 degrees with respect to the subject, whose experienced position and visuo-spatial perspective does not change. There is neither disembodiment nor autoscopy.

The ability to recognize oneself as the agent of a behavior or thought.

Experience of seeing parts of one's own body (generally a limb) as modified in shape, position, number, or movement with respect to their habitual appearance. The point of view and the direction from which the subject experiences seeing.
Human Brain; 2003 Jun 19-22; New York, NY. Available on CDROM in NeuroImage, Vol. 19, No. 2.

Blanke O, Ortigue S, Landis T, Seeck M. 2002. Stimulating illusory own-body perceptions. Nature 419:269-70.

Bonda E, Petrides M, Frey S, Evans A. 1995. Neural correlates of mental transformations of the body-in-space. Proc Natl Acad Sci U S A 92:11180-4.

Brandt T. 2000. Central vestibular disorders. In: Vertigo: its multisensory syndromes. London: Springer. p 146-67.

Brugger P, Agosti R, Regard M, Wieser HG, Landis T. 1994. Heautoscopy, epilepsy, and suicide. J Neurol Neurosurg Psychiatr 57:838-9.

Brugger P, Regard M, Landis T. 1997. Illusory reduplication of one's own body: phenomenology and classification of autoscopic phenomena. Cogn Neuropsychiatr 2:19-38.

Calvert GA, Campbell R, Brammer MJ. 2000. Evidence from functional magnetic resonance imaging of crossmodal binding in the human heteromodal cortex. Curr Biol 10:649-57.

Daly DD. 1958. Ictal affect. Am J Psychiatr. 115:171-81.

Decety J, Sommerville JA. 2003. Shared representations between self and other: a social cognitive neuroscience view. Trends Cogn Sci 7:527-33.

Denning TR, Berrios GE. 1994. Autoscopic phenomena. Br J Psychiatr 165:808-17.

Devinsky O, Feldmann E, Burrowes K, Bromfield E. 1989. Autoscopic phenomena with seizures. Arch Neurol 46:1080-8.

Downing PE, Jiang Y, Shuman M, Kanwisher N. 2001. A cortical area selective for visual processing of the human body. Science 293:2470-3.

Farrell MJ, Robertson IH. 2000. The automatic updating of egocentric spatial relationships and its impairment due to right posterior cortical lesions. Neuropsychologia 38:585-95.

Fasold O, von Bevern M, Kuhberg M, Ploner CJ, Vilringer A, Lempert T, Wenzel R. 2002. Human vestibular cortex as identified with caloric vestibular stimulation by functional magnetic resonance imaging. Neuroimage 17:1384-93.
Goodwin GM, McCloskey DI, Matthews PBC. 1972. Proprioceptive illusions induced by muscle vibration: contribution by muscle spindles to perception? Science 175:1382-4.

Green CE. 1968. Out-of-body experiences. London: Hamish Hamilton.

Grossman E, Donnelly M, Price R, Pickens D, Morgan V, Neighbor G, and others. 2000. Brain areas involved in perception of biological motion. J Cogn Neurosci 12:711-20.

Grüsser OJ, Landis T. 1991. The splitting of "I" and "me": heautoscopy and related phenomena. In: Visual agnosias and other disturbances of visual perception and cognition. Amsterdam: MacMillan. $p$ 297-303.

Halligan PW. 2002. Phantom limbs: the body in mind. Cogn Neuropsychiatr 7:251-68.

Halligan PW, Fink GR, Marshal JC, Vallar G. 2003. Spatial cognition: evidence from visual neglect. Trends Cogn Sci 7:125-33.

Hécaen H, Ajuriaguerra J. 1952. L’Héautoscopie. In: Méconnassiances et hallucinations corporelles. Paris: Masson. p 310-43.

Hécaen H, Green A. 1957. Sur l'héautoscopie. Encephale 46:581-94.

Irwin HJ. 1985. Flight of mind: a psychological study of the out-ofbody experience. Metuchen (NJ): Scarecrow Press.

Kölmel HW. 1985. Complex visual hallucinations in the hemianopic field. J Neurol Neurosurg Psychiatry 48:29-38.

Lackner JR. 1988. Some proprioceptive influences on the perceptual representation of body shape and orientation. Brain 111:281-97.

Lackner JR. 1992. Sense of body position in parabolic flight. Ann N Y Acad Sci 656:329-39.

Leube DT, Knoblich G, Erb M, Grodd W, Bartels M, Kircher TT. 2003. The neural correlates of perceiving one's own movements. Neuroimage 20:2084-90.

Lippman CW. 1953. Hallucination of physical duality in migraine. J Nerv Ment Dis 117:345-50.

Lobel E, Kleine J, Leroy-Wilig A. 1999. Functional MRI of galvanic vestibular stimulation. J Neurophysiol 80:2699-709.

Lunn V. 1970. Autoscopic phenomena. Acta Psychiatr Scand 46(Suppl 219):118-25. 
Maguire EA, Burgess N, Donnett JG, Frackowiak RS, Frith CD, O'Keefe J. 1998. Knowing where and getting there: a human navigation network. Science 280:921-4.

Melzack R. 1990. Phantom limbs and the concept of a neuromatrix. Trends Neurosci 13:88-92.

Metzinger T. 2003. Being no one. Cambridge (MA): MIT Press.

Mittelstaedt H, Glasauer S. 1993. Illusions of verticality in weightlessness. Clin Invest 71:732-9.

Neisser U. 1988. The five kinds of self-knowledge. Phil Psychol $1: 35-59$.

Palmer J. 1978. The out-of-body experience: a psychological theory. Parapsychol Rev 9:19-22.
Ramachandran VS, Hirstein W. 1998. The perception of phantom limbs. Brain 121:1603-30.

Ruby P, Decety J. 2001. Effect of subjective perspective taking during simulation of action: a PET investigation of agency. Nat Neurosci 4:546-50.

Sheils D. 1978. A cross-cultural study of beliefs in out-of-the-body experiences, waking and sleeping. J Soc Psych Res 49:697-741.

Smith BH. 1960. Vestibular disturbances in epilepsy. Neurol 10:465-9.

Zacks JM, Ollinger JM, Sheridan MA, Tversky B. 2002. A parametric study of mental spatial transformations of bodies. Neuroimage 16:857-72. 